\title{
Prevalência dos microrganismos isolados em unidades de terapia intensiva de um hospital universitário
}

Daniela Zanini ${ }^{1}$

\section{RESUMO}

O presente trabalho demonstra o perfil etiológico e de sensibilidade dos microrganismos isolados dos pacientes atendidos nas Unidades de Terapia Intensiva Neonatal e Pediátrica do Hospital Universitário de Santa Maria, durante o período de julho a dezembro de 2008. Para o presente estudo, foram computados os dados provenientes de espécimes como sangue, swab anal, lavado de cânula, ponta de cateter e swab ocular. Os materiais mais frequentemente enviados ao laboratório foram: hemoculturas $(55,1 \%)$, swab anais $(23,8 \%)$ e lavados de cânula $(9,7 \%)$. A maior positividade quanto ao crescimento de microrganismos ocorreu nas amostras de swab anal $(79,6 \%)$ e swab ocular $(60,0 \%)$. Os microrganismos mais isolados foram Staphylococcus spp. e Candida spp. Um montante significativo de amostras apresentou resistência aos antimicrobianos testados. Na família Staphylococcaceae, $97 \%$ foram cepas produtoras de $\beta$-lactamase, $78,3 \%$ foram resistentes à oxacilina e $69,6 \%$ foram resistentes à eritromicina. Na família Enterobacteriaceae, $72,7 \%$ foram resistentes à ampicilina e tobramicina, $63,6 \%$ foram resistentes à gentamicina e $27,3 \%$ cepas foram produtoras de ESBL. Com base nesses dados é possível adotar medidas para a eleição da correta terapia antimicrobiana e $\mathrm{o}$ uso racional de fármacos.

Descritores: Infecção Hospitalar; Vigilância Epidemiológica; Resistência Bacteriana.

\section{Prevalence of microorganisms isolated from intensive care units in a university hospital}

\begin{abstract}
This paper demonstrates the etiologic profile and sensitivity of organisms isolated from patients treated in the Neonatal Intensive Care Unit of the University Hospital of Santa Maria, during the period from July to December 2008. For this study, data from specimens such as blood cultures, anal swab, washed cannula, catheter tip and ocular swabs were computed. The materials most often sent to the laboratory were: blood cultures (55.1\%), anal swab $(23.8 \%)$ and washed cannula (9.7\%). The most positive about the growth of microorganisms occurred in anal swab samples $(79.6 \%)$ and ocular swab (60.0\%). The most common microorganisms isolated were Staphylococcus spp. and Candida spp. A significant amount of samples were resistant to antimicrobials. In family Staphylococcaceae, $97 \%$ were strains producing $\beta$-lactamase, $78.3 \%$ were resistant to oxacillin and $69.6 \%$ were resistant to erythromycin. In the family Enterobacteriaceae, $72.7 \%$ were resistant to ampicillin and tobramycin, $63.6 \%$ were resistant to gentamicin and $27.3 \%$ strains were ESBL producers. Based on these data it is possible to implement measures for the election of the correct antimicrobial therapy and the rational use of drugs.
\end{abstract}

Descriptors: Nosocomial Infection; Epidemiologic Vigilance; Resistance Bacterial. 


\section{Introdução}

A terapia intensiva pediátrica é uma especialidade médica relativamente jovem, tendo se consolidado há cerca de 50 anos, após uma epidemia de poliomielite na Escandinávia. ${ }^{1}$ No Brasil, esta especialidade experimentou grande desenvolvimento nos últimos 20 anos, acompanhando de certa forma a tendência mundial, ${ }^{2}$ sendo observado grande avanço no conhecimento médico referente ao atendimento de pacientes criticamente doentes (medicina intensiva), com modificações significativas na evolução e prognóstico dessas pessoas. ${ }^{3}$

Apesar do intenso avanço científico e tecnológico e da eficiência no reconhecimento de novos agentes infecciosos, as infecções hospitalares continuam sendo um sério problema de saúde pública. A problemática se agrava nas unidades de terapia intensiva, já que, neste ambiente, o paciente está mais exposto ao risco de infecção, haja vista sua condição clínica e a variedade de procedimentos invasivos rotineiramente realizados. ${ }^{4,5}$

O Center for Disease Control and Prevention (CDC) considera como hospitalares as infecções adquiridas intraparto, durante a hospitalização ou adquiridas até 48 horas após a alta, com exceção das infecções transplacentárias, sendo considerada infecção hospitalar de origem materna aquela que ocorre até 48 horas de vida e infecção hospitalar de origem ambiental aquela que ocorre após 48 horas de vida. ${ }^{6}$

No Brasil, a Portaria $n^{0} 2.616 / 98$ do Ministério da Saúde, a qual regulamenta as ações de controle de infecção hospitalar no país, classifica toda a infecção neonatal como hospitalar, exceto aquelas adquiridas por via transplacentária ou associadas à rotura de membranas amnióticas por período superior a 24 horas antes do parto. ${ }^{7}$

É destacado que na UTI os pacientes têm de 5 a 10 vezes mais probabilidade de contrair infecção e que esta pode representar cerca de $20 \%$ do total de infecções de um hospital. Cabe ressaltar que o risco de infecção é diretamente proporcional à gravidade da doença, às condições nutricionais, à natureza dos procedimentos diagnósticos ou terapêuticos, bem como, ao tempo de internação, dentre outros aspectos. ${ }^{5}$

Quando nos referimos a crianças internadas em unidades de terapia intensiva os fatores de risco gerais para a aquisição de infecções hospitalares são idade menor de dois anos, gravidade da doença de base, procedimentos invasivos (ventilação mecânica, cateter venoso central etc.), tempo de permanência hospitalar elevado, densidade populacional, relação paciente-enfermaria e o uso prévio de antibióticos de amplo espectro. Quanto ao uso de antibióticos, parece haver uma estreita e consagrada interação entre resistência bacteriana e a ocorrência de infecções hospitalares. , $^{\circ}$

Enquanto a administração de agentes antimicrobianos salva vidas no tratamento de crianças infectadas, há riscos substanciais quando se faz uso dos mesmos para o tratamento das infecções. Um desses riscos é que nos recém-nascidos a flora bacteriana normal ainda não se estabeleceu e eles estão desprovidos da proteção que esses microrganismos poderiam proporcionar. Assim, quando são tratados com antibióticos de largo espectro, sua flora normal escassa pode ser eliminada. Por esse motivo, os neonatos que ingressam nas UTIs são colonizados rapidamente com os germes hospitalares, inclusive com cepas possuidoras de resistência adquirida a alguns antibióticos. ${ }^{9}$

Além dos fatores de risco para infecção dos recém-nascidos relatados anteriormente, deve-se destacar que há necessidade de manuseio intenso pelos profissionais da saúde que cuidam de sua assistência, aumentando a probabilidade de colonização do recém-nascido com a flora bacteriana existente no ambiente e nas mãos daqueles profissionais. Assim, a transmissão cruzada constitui a principal forma de disseminação de microrganismos no hospital, principalmente em unidades superlotadas e com redução numérica de funcionários. ${ }^{6}$

A vigilância epidemiológica faz parte de um conjunto de atividades que levam à observação ativa, sistemática e contínua da ocorrência de infecções hospitalares. Essas ações de controle visam: determinar o perfil epidemiológico das infecções hospitalares; definir surtos ou epidemias; definir fatores de risco específicos de acordo com o tipo de paciente; e fornecer informações à equipe hospitalar sobre os cuidados necessários ao controle e prevenção das infecções hospitalares. ${ }^{10}$

Contudo, cabe destacar, que, no Brasil, os dados sobre infecção hospitalar são pouco divulgados. Além disso, esses dados não são consolidados por muitos hospitais, o que dificulta o conhecimento da dimensão do problema no país. ${ }^{4}$ É, portanto, de grande importância o conhecimento da epidemiologia das infecções hospitalares, sendo necessários estudos nacionais abrangentes vinculados a um sistema unificado para determinação dos agentes etiológicos, da resistência bacteriana, dos fatores envolvidos no prolongamento do tempo de internação, fatores de risco, letalidade, entre outros. 8 Esses conhecimentos serão bastante úteis para o estabelecimento e implantação de medidas de controle e prevenção cada vez mais eficazes. Sendo assim, é nesse contexto que objetiva-se determinar o perfil etiológico e de sensibilidade dos microrganismos isolados das Unidades de Terapia Intensiva Neonatal e Pediátrica do Hospital Universitário de Santa Maria (HUSM), Santa Maria, RS. 


\section{Metodologia}

\section{Considerações éticas}

Este trabalho trata-se de uma análise de dados secundários, na qual os sujeitos da pesquisa não foram abordados. Dessa forma, não há implicações éticas pelo fato de que nome, sexo, idade, estado civil, bem como outras informações do estado da saúde dos sujeitos não constam entre os dados analisados. ${ }^{11}$

Para realização do presente trabalho, foram analisadas todas as solicitações de exames microbiológicos, referentes ao período de julho a dezembro de 2008, provenientes das Unidades de Terapia Intensiva Neonatal (UTIRN) e Pediátrica (UTIPed) do Hospital Universitário de Santa Maria (HUSM). Os materiais advindos dos pacientes internados nessas unidades eram oriundos de diversos sítios biológicos e foram encaminhados ao Laboratório de Análises Clínicas (LAC) do referido nosocômio.

Foram consideradas positivas todas as culturas em que houve o desenvolvimento de pelo menos um microrganismo. No trabalho em questão, porém, foram selecionados para análise apenas os materiais que foram enviados ao LAC com maior frequência como, por exemplo, sangue, swab anal, lavado de cânula, ponta de cateter e swab ocular.

No LAC do HUSM, as amostras foram identificadas utilizando-se previamente metodologia convencional com os testes da catalase, oxidase e coloração de Gram, seguidos por automação (MicroScan - DADE - SIEMENS ${ }^{\circledR}$ ) e ainda outros testes fenotípicos convencionais de identificação bioquímica dos microrganismos (como uréia, citrato, etc.). 0 teste de sensibilidade aos antimicrobianos (TSA) foi realizado através das metodologias de disco-difusão, segundo o Clinical and Laboratory Standards Institute,$^{12}$ e automatizada semiquantitativa. ${ }^{12}$

\section{Resultados e Discussão}

No período de seis meses, de julho a dezembro de 2008 foram encaminhadas 809 amostras com solicitações de exames bacteriológicos para o LAC do HUSM, provenientes de diversos materiais biológicos coletados de pacientes das UTIRN e UTIPed. Um total de 518 (64,0\%) amostras foram consideradas negativas e 291 (36,0\%) positivas. Isto porque, após a semeadura do espécime clínico em meios de cultura adequados e incubação em estufa $35^{\circ} \mathrm{C} \pm 2^{\circ} \mathrm{C}$, por período de 24 - 48 horas, houve o desenvolvimento de pelo menos um microrganismo em quantidade significativa.

Na elaboração do presente trabalho, computou-se somente os dados provenientes dos materiais mais frequentemente solicitados para análises que foram: sangue, swab anal, lavado de cânula, ponta de cateter e swab ocular. Utilizando esse critério, das 809 amostras totais, 617 foram analisadas e destas, $241(39,1 \%)$ foram consideradas positivas e 376 $(60,9 \%)$ negativas.

Dessas 617 amostras selecionadas no estudo, 340 (55,1\%) foram de sangue, $147(23,8 \%)$ de swab anal, 60 (9,7\%) de lavado de cânula, $35(5,7 \%)$ de ponta de cateter e $35(5,7 \%)$ de swab ocular.

A Figura 1 mostra o número de solicitações de cultura de cada material correlacionando com sua positividade.

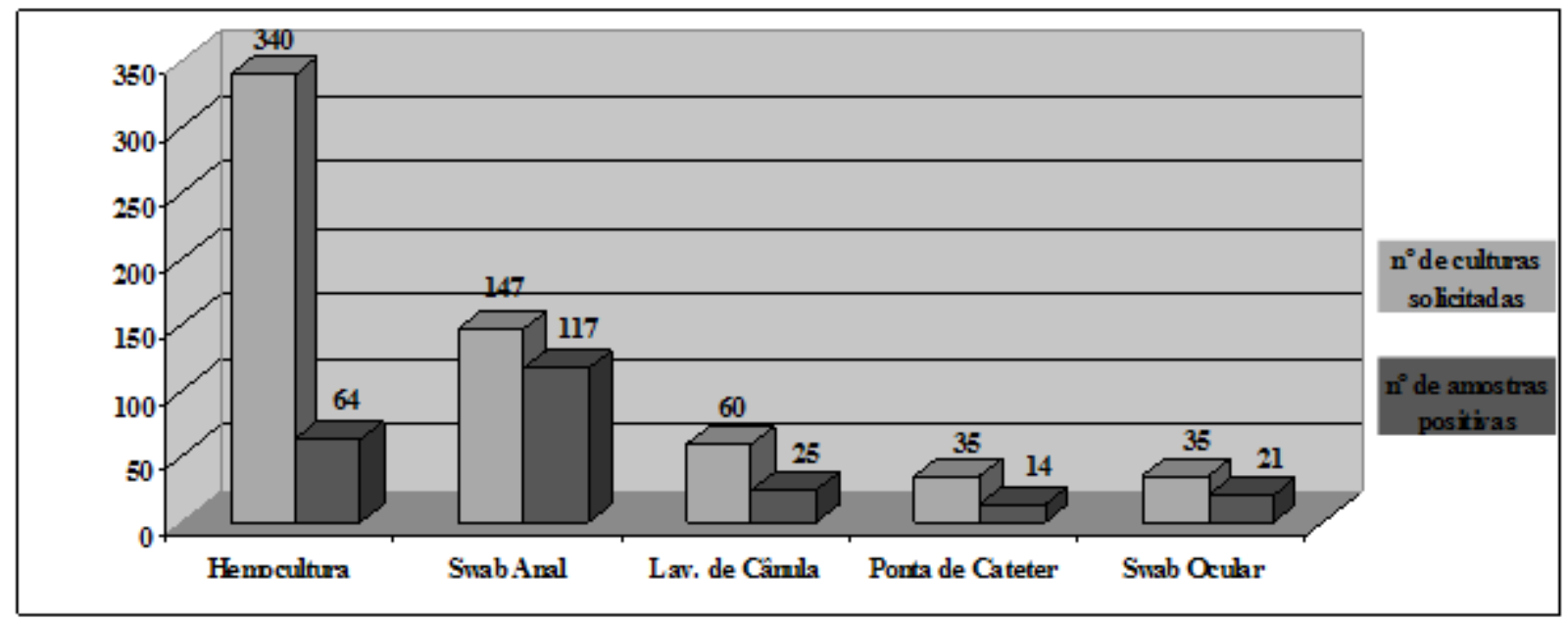

Figura 1 - Correlação entre o número de culturas solicitadas e a positividade das amostras dos materiais mais frequentemente enviados ao LAC-HUSM, no período de julho a dezembro de 2008, pelas UTIRN e UTIPed 
Nas 241 amostras positivas, 368 microrganismos foram isolados porque em $90(37,3 \%)$ delas houve o desenvolvimento de mais de um microrganismo. Desses 368 microrganismos isolados, 164 (44,6\%) foram cocos Gram-positivos, 163 (44,3\%) bacilos Gram-negativos e 41 (11,1\%) fungos do gênero Candida.

A Tabela 1 relaciona os microrganismos isolados com maior frequência com os espécimes clínicos.

Tabela 1 - Perfil etiológico dos microrganismos isolados com maior frequência e respectivos espécimes clínicos, das culturas realizadas na UTIRN e UTIPed do HUSM - Santa Maria - RS, no período de no período de julho a dezembro de 2008.

\begin{tabular}{|c|c|c|c|c|c|c|c|c|c|c|}
\hline \multirow{3}{*}{ Microrganismo } & \multicolumn{10}{|c|}{ Número de isolamentos por amostra clínica } \\
\hline & \multicolumn{2}{|c|}{ Swab Anal } & \multicolumn{2}{|c|}{ Hemocultura } & \multicolumn{2}{|c|}{ Lavado de Cânula } & \multicolumn{2}{|c|}{ Swab Ocular } & \multicolumn{2}{|c|}{ Ponta Cateter } \\
\hline & $n^{0}$ & $\%$ & $n^{0}$ & $\%$ & $n^{0}$ & $\%$ & $n^{0}$ & $\%$ & $n^{0}$ & $\%$ \\
\hline \multicolumn{11}{|l|}{ Cocos Gram-positivos } \\
\hline Staphylococcus aureus & 0 & (0) & 0 & (0) & 0 & (0) & 7 & $(25,9)$ & 0 & $(0)$ \\
\hline Staphylococcus epidermidis & 0 & (0) & 24 & $(36,4)$ & 12 & $(38,7)$ & 8 & $(29,6)$ & 5 & $(31,2)$ \\
\hline SCN (que não o S. epidermidis) & 0 & (0) & 11 & $(16,7)$ & 0 & $(0)$ & 0 & (0) & 2 & $(12,5)$ \\
\hline Staphylococcus sp. & 60 & $(26,3)$ & - & - & - & - & - & - & - & - \\
\hline Streptococcus sp. & 24 & $(10,5)$ & & - & - & - & - & - & - & - \\
\hline \multicolumn{11}{|l|}{ Bacilos Gram-negativos } \\
\hline Klebsiella pneunoniae & 24 & $(10,5)$ & 0 & $(0)$ & 3 & $(9,7)$ & 3 & $(11,5)$ & 0 & (0) \\
\hline Escherichia coli & 0 & $(0)$ & 0 & (0) & 3 & $(9,7)$ & 0 & $(0)$ & 0 & (0) \\
\hline Serratia marcescens & 0 & $(0)$ & 0 & $(0)$ & 0 & (0) & 0 & (0) & 2 & $(12,5)$ \\
\hline \multicolumn{11}{|l|}{ Fungos } \\
\hline Candida sp. & 25 & $(11,0)$ & 11 & $(16,7)$ & 0 & (0) & 0 & (0) & 3 & $(18,7)$ \\
\hline
\end{tabular}

Nas Tabelas 2, 3 e 4 estão os perfis de sensibilidade dos Staphylococcus spp., Família Enterobacteriaceae e Klebsiella pneumoniae, respectivamente, aos antimicrobianos do Grupo A (testados e reportados na rotina), segundo o CLSI 2008.

Tabela 2 - Perfil de sensibilidade dos estafilococos isolados de amostras dos pacientes assistidos pelas UTIRN e UTIPed do HUSM - Santa Maria - RS, no período de julho a dezembro de 2008, frente aos antimicrobianos do Grupo A (CLSI 2008), utilizando metodologia de disco difusão e/ou automatizada.

\begin{tabular}{|c|c|c|c|c|c|c|c|}
\hline \multicolumn{8}{|c|}{ Staphylococcus spp. } \\
\hline & \multicolumn{2}{|c|}{ Sensível } & \multicolumn{2}{|c|}{ Intermediário } & \multicolumn{2}{|c|}{ Resistente } & \multirow[t]{2}{*}{ Total } \\
\hline & $n^{0}$ & $(\%)$ & & $(\%)$ & $n^{0}$ & $(\%)$ & \\
\hline Eritromicina & 20 & $(29,0)$ & 0 & $(0,0)$ & 48 & $(69,6)$ & 68 \\
\hline Clindamicina & 32 & $(46,4)$ & 1 & $(1,4)$ & 33 & $(47,8)$ & 66 \\
\hline Oxacilina & 14 & $(20,3)$ & 0 & $(0,0)$ & 54 & $(78,3)$ & 68 \\
\hline Penicilina & 01 & $(1,4)$ & 0 & $(0,0)$ & $\mathrm{BLAC}$ & $7 \quad(97,1)$ & 68 \\
\hline Sulfametoxazol- Trimetoprim & 03 & $(52,2)$ & 0 & $(0,0)$ & 31 & $(44,9)$ & 67 \\
\hline
\end{tabular}

Obs.: No laudo de dados uma amostra não constava o TSA do microrganismo isolado; para dois microrganismos não constava a sensibilidade à clindamicina; e para um microrganismo não constava a sensibilidade frente ao sulfametoxazol-trimetoprim. 
Tabela 3 - Perfil de sensibilidade dos microrganismos isolados de amostras dos pacientes atendidos pelas UTIRN e UTIPed do HUSM - Santa Maria - RS, no período de julho a dezembro de 2008, frente aos antimicrobianos do Grupo A (CLSI 2008), utilizando metodologia de disco difusão e/ou automatizada.

\begin{tabular}{|c|c|c|c|c|c|c|c|}
\hline \multicolumn{8}{|c|}{ Enterobacteriaceae } \\
\hline & \multicolumn{2}{|c|}{ Sensível } & \multicolumn{2}{|c|}{ Intermediário } & \multicolumn{2}{|c|}{ Resistente } & Total \\
\hline & $n^{0}$ & $\%$ & $n^{0}$ & $\%$ & $n^{0}$ & $\%$ & \\
\hline Ampilicina & 0 & (0) & 0 & (0) & 8 & $(72,7)$ & 8 \\
\hline \multirow[t]{2}{*}{ Cefazolina } & 2 & $(18,2)$ & 0 & (0) & $\mathrm{ESBL}^{* *} 3$ & $(27,3)$ & 8 \\
\hline & & & & & 3 & $(27,3)$ & \\
\hline \multirow[t]{2}{*}{ Cefalotina } & 2 & $(18,2)$ & 0 & (0) & $\mathrm{ESBL}^{* *} 3$ & $(27,3)$ & 8 \\
\hline & & & & & 3 & $(27,3)$ & \\
\hline Gentamicina & 3 & $(27,3)$ & 1 & $(9,3)$ & 7 & $(63,6)$ & 11 \\
\hline Tobramicina & 3 & $(27,3)$ & 0 & (0) & 8 & $(72,7)$ & 11 \\
\hline
\end{tabular}

${ }^{*}$ BLAC são cepas produtoras de $\beta$-lactamase, que inativam o anel $\beta$-lactâmico da penicilina.

** Essas foram cepas de Klebsiella pneumoniae produtoras de $\beta$-lactamase de espectro ampliado, capazes de inativar uma grande variedade de antibióticos $\beta$-lactâmicos, incluindo as cefalosporinas e os monobactâmicos.

Obs.: Para três microrganismos o laudo não constava da sensibilidade dos mesmos frente à amplicilina, cefazolina e cefalotina.

Tabela 4 - Perfil de sensibilidade da K. pneumoniae isolada de amostras dos pacientes atendidos pelas UTIRN e UTIPed do HUSM - Santa Maria - RS, no período de julho a dezembro de 2008, frente aos antimicrobianos do Grupo A (CLSI 2008), utilizando metodologia de disco difusão e/ou automatizada.

\begin{tabular}{|c|c|c|c|c|c|c|c|}
\hline \multicolumn{8}{|c|}{ Enterobacteriaceae } \\
\hline & \multicolumn{2}{|c|}{ Sensível } & \multicolumn{2}{|c|}{ Intermediário } & \multicolumn{2}{|c|}{ Resistente } & Total \\
\hline & $n^{0}$ & $\%$ & $n^{0}$ & $\%$ & $n^{0}$ & $\%$ & \\
\hline Ampilicina & 0 & (0) & 0 & (0) & 4 & $(66,7)$ & 4 \\
\hline Cefazolina & 2 & $(33,3)$ & 0 & (0) & $\mathrm{ESBL}^{* *} 3$ & $(50,0)$ & 5 \\
\hline Cefalotina & 2 & $(33,3)$ & 0 & (0) & $\mathrm{ESBL}^{* *} 3$ & $(50,0)$ & 5 \\
\hline Gentamicina & 3 & $(33,3)$ & 1 & $(16,7)$ & 3 & $(50,0)$ & 6 \\
\hline Tobramicina & 3 & $(33,3)$ & 0 & (0) & 4 & $(66,7)$ & 6 \\
\hline
\end{tabular}

Obs.: O laudo não constava da sensibilidade de 2 cepas frente à amplicilina e 1 cepa frente à cefazolina e à cefalotina.

O resultado desta pesquisa revelou que amostras de sangue $340(55,1 \%)$ foi o material mais frequentemente solicitado para análise no LAC-HUSM pelas UTIRN e UTIPed. Porém, pela análise da Figura 1, verificamos que 0 material que apresentou maior positividade quanto ao desenvolvimento de microrganismos foi swab anal, onde 117 $(79,6 \%)$ das 147 amostras foram consideradas positivas. Essas culturas de swab anal representam as culturas de vigilância epidemiológica, realizadas periodicamente com a finalidade de conhecer os microrganismos que colonizam os pacientes da unidade e evitar a ocorrência de surtos, além da pesquisa do Enterococcus spp. vancomicina resistente (EVR).

No período em que o estudo foi realizado não foi detectado nenhum EVR. Por consenso da Comissão de Controle de Infecção Hospitalar (CCIH) do HUSM, no laudo dessas culturas de swab anal, que fazem parte das culturas de vigilância epidemiológica, são liberadas somente as identificações bioquímicas dos microrganismos presentes, sem o TSA.

As hemoculturas lideraram o número de solicitações (Figura 1). Das $340(55,1 \%)$ amostras enviadas ao LACHUSM, 64 (18,8\%) foram positivas. Esta frequência está de acordo com a literatura nacional, a qual destaca que em neonatos as bacteremias são as infecções mais frequentes, representando 30,7\% das infecções observadas na investigação de PESSOA-SILVA et al. ${ }^{13}$ Esses elevados índices para a ocorrência de bacteremias hospitalares em 
crianças, em geral associam-se ao sistema imune imaturo e à frequente exposição a procedimentos invasivos, como as cateterizações venosas profundas. ${ }^{14,15}$

Em nosso estudo, porém, não podemos afirmar que a porta de entrada das bacteremias são os cateteres, pois a positividade das culturas de ponta de cateter $(40,0 \%)$ foi superior à positividade das hemoculturas (18,8\%). O S. epidermidis $24(36,4 \%)$ foi o microrganismo isolado com maior frequência nas hemoculturas, seguido pelos SCN - que não o S. epidermidis - 11 $(16,7 \%)$ e Candida sp. 11 (16,7\%). Os SCN constituíram a maior causa de bacteremias adquiridas em ambiente hospitalar, nos pacientes mantidos em UTIs neonatais, com Candida spp. aparecendo nas quatro primeiras colocações. Estes resultados concordam com o descrito na literatura. ${ }^{16}$

No Brasil, outro estudo também revela que o microrganismo prevalente nas bacteremias adquiridas em unidades hospitalares pediátricas também foi o S. epidermidis. ${ }^{16}$ Contudo, há autores que desconsideram esta bactéria como agente etiológico de bacteremias, uma vez que seu isolamento pode estar relacionado a problemas de assepsia da pele, já que ele faz parte da sua flora residente. ${ }^{17}$

Até duas décadas atrás, os SCN, incluindo o S. epidermidis, eram considerados bactérias comensais. No entanto tornaramse patogênicas na medida em que se universalizou o uso de antissépticos para a pele e para o coto umbilical. ${ }^{18}$

$\mathrm{O}$ isolamento de SCN de amostras de sangue de recém-nascidos com sinais e sintomas de sepse deve ser considerado, porém, ele pode representar uma contaminação por falha na assepsia. Por essa razão, constitui boa recomendação o seu isolamento em duas amostras de sangue dentro de 24 horas, ou que ele seja isolado em duas amostras de sangue e tenha resistência a mais de seis antibióticos, incluindo a oxacilina. ${ }^{19}$

Em nosso estudo Candida spp. teve prevalência significativa tanto nas hemoculturas como nas culturas de ponta de cateter. Os procedimentos invasivos utilizados nos neonatos, em particular os de baixo peso ao nascer, têm sido responsáveis pelo aumento da incidência das infecções fúngicas nessa população. ${ }^{19}$

As infecções hospitalares causadas por fungos representam atualmente um problema crescente de saúde pública em muitos países. Nos Estados Unidos, por exemplo, a prevalência de infecções fúngicas passou de 6\%, em 1980, para 10,4\%, em 1990, segundo o Sistema de Vigilância das Infecções Hospitalares daquele país. Destas, cerca de $80 \%$ foram causadas por leveduras do gênero Candida. ${ }^{20}$

Das 60 amostras de lavado de cânula (Figura 1), 25 (41,7\%) foram positivas. 0 desenvolvimento de infecção associada à intubação orotraqueal ou nasotraqueal pode ser atribuída ao trauma físico da passagem do tubo e à contaminação por meio das mãos dos profissionais da saúde. ${ }^{21}$ Os tubos traqueais abolem o reflexo da tosse, diminuem a motilidade ciliar e propiciam a colonização do trato aéreo inferior com bactérias da orofaringe e da via aérea superior.21 O S. epidermidis foi o agente mais isolado, (12 - 38,7\%). Dados semelhantes foram descritos por LOPES et al. (2008), em um estudo efetuado no Hospital Universitário de Londrina-PR. Eles justificaram a prevalência e representatividade do $S$. epidermidis pelo fato de ele ser uma espécie colonizante da pele, sendo frequentemente inoculado durante procedimentos invasivos ou veiculado pela equipe de saúde.

Das amostras de swab ocular, $21(60 \%)$ foram positivas (Tabela 1). Os microrganismos mais isolados nesse material foram Staphylococcus epidermidis 8 (29,6\%), Staphylococcus aureus 7 (25,9\%) e Klebsiella pneumoniae 3 (11,5\%). Este resultado está de acordo com o descrito por ENDRESS et al. (2009) que também verificou uma prevalência de SCN e Staphylococcus aureus em culturas de swab ocular de recém-nascidos internados de UTIs. ${ }^{22}$

Essa elevada positividade das amostras de swab ocular poderia ser justificada pela ocorrência de partos normais, porque, durante o parto transpelviano, uma variedade de microrganismos albergados pela mãe no trato genital podem invadir o saco conjuntival do neonato, causando infecções oculares. Porém, dados estatísticos do HUSM revelam que, de julho a dezembro de 2008 , aproximadamente $63,0 \%$ dos partos foram por cesariana e $37,0 \%$ normais. ${ }^{23}$ Portanto, a elevada positividade das amostras de swab ocular não tem correlação com o tipo de parto.

O Staphylococcus epidermidis faz parte da flora permanente da pele; então podemos aferir que, pelo fato de os neonatos internados em UTIs serem submetidos a processos de intubação endotraqueal e colocação de sondas nasogástricas, esta manipulação sobre a face do paciente favorece a ocorrência de infecções oculares pelo $S$. epidermidis como citado no estudo de CARVALHO \& MARQUES (1999). A expressiva frequência do isolamento de $S$. aureus nas amostras de swab ocular é condizente com a literatura, que apresenta esse patógeno como principal agente de conjuntivite e outras doenças oculares. ${ }^{22}$

Das 35 amostras de ponta de cateter enviadas ao LAC-HUSM, 14 (40\%) tiveram culturas positivas (Método de Maki) sendo que S. epidermidis foi o microrganismo prevalente $5(31,2 \%)$. Estes dados estão de acordo com estudos realizados em outros nosocômios brasileiros, nos quais $S$. epidermidis (27\%) foi o mais frequente, seguido por $S$. aureus (16\%), Enterococcus spp. (8\%) e Candida spp. (8\%). ${ }^{24,25}$ 
É neste cenário que a resistência aos antimicrobianos tem sido identificada com maior frequência e relatos na literatura apontam que mais de $80 \%$ das cepas de $S$. epidermidis e pelo menos $60 \%$ das cepas de $S$. aureus, causadores de infecções nosocomiais em unidades neonatais, são resistentes à meticilina/oxacilina. ${ }^{6}$

Essa elevada resistência foi verificada também em nosso estudo (Tabela 2), onde 67 (97,1\%) Staphylococcus spp. apresentaram resistência à penicilina, 54 (78,3\%) à meticilina/oxacilina (MRSA/MRS) e 48 (69,6\%) à eritromicina.

Entre os representantes da família Enterobacteriaceae, (Tabela 3) 8 (72\%) apresentaram resistência à ampicilina e tobramicina, 7 (63\%) apresentaram resistência à gentamicina e $6(55 \%)$ apresentaram resistência à cefalotina e cefazolina. Destes, metade foram classificados como ESBL ( $\beta$-lactamase de espectro ampliado). As $\beta$-lactamases são enzimas com considerável atividade de hidrólise, que inativam uma grande variedade de antibióticos $\beta$-lactâmicos, incluindo as penicilinas de amplo espectro, cefalosporinas de $1^{\mathrm{a}}, 3^{\mathrm{a}}$ e $4^{\mathrm{a}}$ gerações e o monobactâmico aztreonam. ${ }^{26}$

Entre os representantes da família Enterobacteriacea, o microrganismo mais isolado foi $K$. pneumoniae e pela análise da Tabela 4 verificamos que 4 (66,7\%) apresentaram resistência à ampicilina e tobramicina, $3(50,0 \%)$ apresentaram resistência à gentamicina e $3(50,0 \%)$ apresentaram resistência à cefalotina e cefazolina e estas foram classificadas como ESBL. A falta de adoção de medidas específicas de controle de infecção hospitalar e a utilização cada vez mais frequente de procedimentos invasivos e antibióticos de largo espectro, como cefalosporinas de $3^{\mathrm{a}}$ e $4^{\mathrm{a}}$ gerações, certamente correlacionam-se com esse acontecimento. ${ }^{26}$

\section{Conclusão}

O elevado nível de tecnologia empregado nas UTIs trouxe o prolongamento da sobrevida dos pacientes, porém, nestas unidades, as infecções hospitalares têm se revelado como uma das mais frequentes complicações no tratamento.

Quando a clientela admitida em UTIs são crianças a situação é ainda mais grave. A natural imaturidade imunológica associada aos fatores a que estão expostos durante o tratamento como, por exemplo, os procedimentos altamente invasivos e a transmissão cruzada de patógenos resultam em taxas de infecção hospitalar superiores às de outras populações.

Frente a tantos processos infecciosos, o uso de agentes antimicrobianos nestas situações torna-se inevitável, contudo, o uso indiscriminado de antibióticos de largo espectro além de eliminar a flora microbiológica normal protetora dos RN também favorece a colonização dos neonatos por germes hospitalares, especialmente por cepas possuidoras de resistência a alguns antibióticos.

A frequência de microrganismos que causaram infecções nos pacientes da UTIRN e UTIPed e que apresentaram mecanismos de resistência aos antimicrobianos em nosso estudo apresentou índices elevados e, por isto, evidenciamos a necessidade do uso racional de antimicrobianos em UTIs infantis tanto para o sucesso da terapêutica instituída, quanto para que ocorra uma menor pressão seletiva de microrganismos nestas unidades.

O conhecimento do perfil etiológico das infecções e o perfil de sensibilidade dos microrganismos isolados nos principais materiais clínicos enviados para análise em setores de microbiologia, portanto, é fundamental para a prevenção da resistência bacteriana, para a elaboração de recomendações da terapia antimicrobiana empírica para a unidade e para o uso racional de fármacos.

\section{Referências Bibliográficas}

1. Souza DC, Troster EJ, Carvalho WB, Shin SH, Cordeiro AMG. Disponibilidade de unidades de terapia intensiva pediátrica e neonatal no município de São Paulo. J. Pediatr. 2004; 80(6):456-60.

2. Barbosa AP. Terapia intensiva neonatal e pediátrica no Brasil: o ideal, o real e o possível. J. Pediatr. 2004; 80:437-8.

3. Silva LJ, Silva LR, Christoffel MM. Tecnologia e humanização na Unidade de Terapia Intensiva Neonatal: reflexões no contexto do processo saúde-doença. Rev Esc Enferm USP. 2009; 43(3):684-9.

4. Turrini RNT, Santos AH. Infecção hospitalar e causas múltiplas de morte. J. Pediatr. 2002; 78(6):485.

5. Lima ME, Andrade D, Hass VJ. Avaliação da Prospectiva da Ocorrência de Infecção em Pacientes Críticos de Unidade de Terapia Intensiva. Rev. Bras. Ter. Intensiva. 2007; 19(3):342-7. 
6. Missi-Pinhata MM, Nascimento SD. Infecções neonatais hospitalares. J. Pediatr. 2001; 77(1):81-96.

7. Brasil. Ministério da Saúde. Portaria n 2616, de 12 de maio de 1998. Diário Oficial da União, Brasília, DF, 13 mai. 1998.

8. Farhat CK. Infecção hospitalar. J. Pediatr. 2000; 76:259-60.

9. Sarubbi MA. Prevención de infecciones hospitalarias en las unidades de cuidado intensivo neonatal (UCIN). Rev. Hosp. Mater. Infant. Ramón Sarda. 2004; 24(4):148-56.

10. Hinrichsen SL. Biossegurança e controle de infecções: risco sanitário hospitalar. Rio de Janeiro; Medsi; 2004.

11. Oliveira-Filho ABO, Martinelli JM. Casos notificados de malária no Estado do Pará, Amazônia Brasileira, de 1998 a 2006. Epidemiol. Serv. Saúde. 2009; 18(3):277-84.

12. Clinical and Laboratory Institute - Performance Standards of Antimicrobial Susceptibility Testing. CLSI document M100-S18 (ISBN 1-56238-556-9) Clinical and Laboratory Institute - 940 - West Valley Road - Suite 1400 - Wayne, Pennsylvania 19087 - 1898 USA, 2008.

13. Pessoa-Silva CL, Ricchtmann R, Calil R, Santos RMR, Costa MLM, Frota ACC et al. Healthcare-associated infections among neonates in Brazil. Infect Control Hosp Epidemiol. 2004; 25(9):772-7.

14. Macias AE, Munoz JM, Galvan A, Gonzales JA, Medina H, Alpuche $C$ et al. Nosocomial bacteremia in neonates related to poor standards of care. Pediatr Infects Dis J. 2005; 24(4):713-6.

15. Chien L, MacNab Y, Aziz A, Andrews W, McMillan DD, Lee SK. Variations in central venous catheter-related infections risks among Canadian neonatal intensive care units. Pediatr Infects Dis J. 2002; 21(6):505-11.

16. Brito DVD, Soares JP, Abdallah VOS, Filho PPG. Bacteremia por Staphylococcus epidermidis em neonatos: incidência e fatores de risco. Rev Ciênc Med. 2007; 16(2):71-7.

17. Aguilar GM, Arriaga MC. Incidência de bacteriemia y neumonia nosocomial em uma unidade de pediatria. Salud Pública Méx. 2001; 43:515-22.

18. Miura E. Infecção pelo estafilococo coagulase-negativa em recém-nascidos: mito ou verdade? J. Pediatr. 2002; 8(4):255-6.

19. Cordeiro DNG. Dissertação de Mestrado. Significância clínica da presença de Staphylococcus coagulase-negativo isolados de recém-nascidos de uma Unidade de Terapia Intensiva Neonatal em Brasília -DF. Universidade de Brasília, Faculdade de Medicina, 2007.

20. Maluche ME, Santos JI. Candida sp. e infecções hospitalares: aspectos epidemiológicos e laboratoriais. Rev. Bras. Anal. Clin. 2008; 40(1):65-7.

21. Lopes GK, Rossetto EG, Belei RA, Capobiango JD, Matsuo T. Estudo epidemiológico das infecções neonatais no Hospital Universitário de Londrina, Estado do Paraná. Acta Sci. Health Sci. 2008; 30(1):55-63.

22. Endress D, Brandt CT, Castro CMMB, Oliveira VF, Diniz MFA. Microbiota conjuntival e resistência a antibióticos em recém-nascidos prematuros internados em unidades de terapia intensiva. Arq. Bras. Oftalmol. 2009; 72(3):291-5. 23. Ferreira-Filho JP, Lorenzoni M. Indicadores Hospitalares. Serviço de Estatística do Hospital Universitário de Santa Maria. 2008.

24. Marconi C, Cunha MLRS, Lyra JC, Bentlin MR, Batalha JEN, Sugizaki MF et al. Utilidade da cultura de ponta de cateter no diagnóstico de infecção neonatal. J. Pediatr. 2009; 85(1):80-3.

25. Bonvento M. Acessos Vasculares e Infecção Relacionada a Cateter. Rev. Bras. Ter. Intensiva. 2007; 19(2):227-30.

26. Tragante CR, Ceccon MEJR, Falcão MC, Seiti M, Sakita N, Vieira RA. Prevalência de sepse por bactérias Gram negativas produtoras de beta-lactamase de espectro estendido em Unidade de Cuidados Intensivos Neonatal. Rev. Paul. Pediatr. 2008; 26(1):59-63.

\section{Daniela Zanini}

Endereço para correspondência - Avenida Roraima, número 1000, Prédio 18, Departamento de Química, Universidade Federal de Santa Maria, Bairro: Camobi, CEP: 97105-900, Santa Maria, RS, Brasil.

E-mail: dz_daniela@yahoo.com.br

Lattes: http://lattes.cnpq.br/4274315755937442

\section{Enviado em 25 de novembro de 2013.}

\section{Publicado em 15 de setembro de 2014.}

